\title{
Combined use of Ovsynch and progesterone supplementation after artificial insemination in dairy cattle
}

\author{
A. Forro, ${ }^{\star}$ G. Tsousis, $\dagger^{1}$ N. Beindorff, $\ddagger$ R. Sharifi, $§$ L. Jäkel,\# and H. Bollweinll \\ ${ }^{*}$ Clinic for Cattle, University of Veterinary Medicine, 30173 Hannover, Germany \\ †Clinic of Farm Animals, Aristotle University of Thessaloniki, 54627 Thessaloniki, Greece \\ łDepartment of Nuclear Medicine, Charité University of Medicine Berlin, 13353 Berlin, Germany \\ §Institute of Animal Breeding and Genetics, University of Göttingen, 37075 Göttingen, Germany \\ \#Private veterinary clinic, 99310 Arnstadt, Germany \\ IClinic of Reproductive Medicine, University of Zurich, 8057 Zurich, Switzerland
}

\begin{abstract}
The objective of this study was to evaluate the effects of different Ovsynch protocols combined with progesterone (P4) supplementation after artificial insemination (AI) of Holstein-Friesian cows. Cows were randomly synchronized at 52 to $63 \mathrm{~d}$ after parturition with either the classical Ovsynch protocol $\left(\mathrm{GnRH}\right.$ on $\mathrm{d} 0, \mathrm{PGF}_{2 \alpha}$ on d $7, \mathrm{GnRH} 48 \mathrm{~h}$ after $\mathrm{PGF}_{2 \alpha}$ ) or with a modified Ovsynch protocol (second GnRH $60 \mathrm{~h}$ after $\mathrm{PGF}_{2 \alpha}$ ). On d 4 after timed AI (TAI), the cows were blocked by parity and randomly divided into 2 groups. Half of the cows were supplemented with $\mathrm{P} 4(\mathrm{P} 4+)$ by applying a $\mathrm{P} 4$-releasing intravaginal device intravaginally for $14 \mathrm{~d}$, whereas the other half remained untreated (P4-). In $50 \%$ of randomly chosen cows, plasma P4 was measured on d 4, 5, and 18 after TAI. Sonographic pregnancy diagnosis was performed on d 33 after TAI in a total of 398 cows. Health status and body condition score (BCS) of all cows were examined at several stages of the study. Cows in the modified Ovsynch protocol tended to have higher $\mathrm{P} 4$ values on $\mathrm{d} 4$ after TAI than cows in the classical Ovsynch protocol $(2.1 \pm 0.2$ vs. 1.6 $\pm 0.2 \mathrm{ng} / \mathrm{mL}$ ), but no difference in pregnancy per AI (P/AI) was observed between the 2 Ovsynch protocols (38.4\% vs. $44.1 \%$ ). Independent of the Ovsynch protocols, $\mathrm{P} 4+$ cows tended to have higher $\mathrm{P} / \mathrm{AI}$ compared with $\mathrm{P} 4-$ cows $(44.4 \%$ vs. $38.1 \%)$. The retention of fetal membranes and BCS at the time of insemination affected P/AI. Moreover, an interaction between BCS at the time of insemination and $\mathrm{P} 4$ supplementation was apparent; that is, the difference in $\mathrm{P} / \mathrm{AI}$ between $\mathrm{P} 4+$ and $\mathrm{P} 4-$ cows was significant in cows with BCS $\geq 3.25$. Progesterone-supplemented cows showed higher $\mathrm{P} 4$ values on $\mathrm{d} 5(4.9 \pm 0.2$ vs. $2.6 \pm 0.2)$ and $\mathrm{d} 18$
\end{abstract}

Received November 26, 2011.

Accepted April 11, 2012.

${ }^{1}$ Corresponding author: tsousis@vet.auth.gr
$(7.8 \pm 0.2$ vs. $6.3 \pm 0.2)$ after TAI, respectively. In conclusion, the elongation of the time interval between the injections of $\mathrm{PGF}_{2 \alpha}$ and the second $\mathrm{GnRH}$ from 48 to $60 \mathrm{~h}$ had no effect on P/AI. Progesterone supplementation after insemination improved the $\mathrm{P} / \mathrm{AI}$ of the Ovsynch protocols, but this effect was more apparent in cows with $\mathrm{BCS} \geq 3.25$.

Key words: synchronization, progesterone, body condition

\section{INTRODUCTION}

In 1995, Pursley et al. (1995) introduced a hormonal ovulation synchronization protocol with the opportunity of a timed AI (TAI) independent of the stage of the estrous cycle. Today, various modifications of the original Ovsynch model ( $\mathrm{GnRH}$ on $\mathrm{d} 7, \mathrm{PGF}_{2 \alpha}$ on d 9, GnRH on d 10, TAI) exist, particularly regarding the time interval between $\mathrm{PGF}_{2 \alpha}$ and the second GnRH injection (Peters and Pursley, 2003; Brusveen et al., 2008). Time intervals less than $48 \mathrm{~h}$ result in a decrease in pregnancy per AI (P/AI; Pursley et al., 1995; Schmitt et al., 1996; Peters and Pursley, 2003), whereas an interval of $56 \mathrm{~h}$ seems to have a positive effect (Brusveen et al., 2008). An early ovulation, through a reduction of the time between the administration of luteolytic $\mathrm{PGF}_{2 \alpha}$ and the second $\mathrm{GnRH}$ injection, can result to smaller dominant follicles and smaller derived corpora lutea and can reduce plasma progesterone (P4) levels and fertility (Taponen et al., 1999; Peters and Pursley, 2003; Mussard et al., 2007). However, the delay of the second GnRH injection can produce larger follicles and corpora lutea, but can also lead to the aging of oocytes and can compromise embryo quality (Cerri et al., 2009). Thus, a crucial time in the development of the dominant follicle exists, where oocyte maturation and follicle size reach their maximal potential, as stated by Peters and Pursley (2003). In a previous study by our working group, luteal blood flow on $\mathrm{d} 7$ postestrus increased when the second GnRH 
injection of an Ovsynch protocol was given $60 \mathrm{~h}$ after the $\mathrm{PGF}_{2 \alpha}$ compared with $40 \mathrm{~h}$ or to a control group that did not receive the second GnRH. Nevertheless, a comparison of a 60 -h with a 48 -h Ovsynch protocol within one study is missing.

It is accepted that an early and well-established P4 synthesis at the beginning of pregnancy has the most advantageous effect on the development of the embryo (Mann and Lamming, 2001; Green et al., 2005; Stronge et al., 2005; Mann et al., 2006). Therefore, in the last 50 yr, several studies examining the effect of supplementing P4 during early pregnancy have been published (Wiltbank et al., 1956; Robinson et al., 1989; Larson et al., 2007). The results on fertility differ between studies (Mann and Lamming, 1999; Villarroel et al., 2004). Factors influencing the efficiency of $\mathrm{P} 4$ supplementation postinsemination are the first day of supplementation (Mann and Lamming, 1999) and the duration of supplementation (Ghasemzadeh-Nava et al., 2007). Moreover, the concentration of $\mathrm{P} 4$ for supplementation is controversial (Mann et al., 2001). Regarding this last point, the study by Stronge et al. (2005) indicates that an optimum level exists for P4 concentrations on different days in early pregnancy. In addition, cow factors, such as the body condition or metabolism, are well known to influence fertility parameters (Butler, 2000; Pryce et al., 2001; Wathes et al., 2007). Different hypotheses exist regarding the clearance of $\mathrm{P} 4$ in high-yield dairy cows (Inskeep, 2004). The reasons may be multifactorial, but one fact is proven: a high metabolism of $\mathrm{P} 4$ is due to a high liver blood flow (Sangsritavong et al., 2002). Body condition score is a good tool to evaluate the metabolic status of the cow indirectly under field conditions (Edmonson et al., 1989). Although it has been shown that a low BCS has a negative effect on the results of synchronization protocols (Moreira et al., 2000; Yamada, 2005; Souza et al., 2008), it remains unclear whether this could interact with $\mathrm{P} 4$ supplementation after TAI.

It is generally accepted that fertility after TAI is compromised compared with insemination after spontaneous ovulation (Mawhinney et al., 1999), although this opinion has been questioned in recent studies (Cerri et al., 2009). Because the synchronization protocol used can influence the $\mathrm{P} 4$ levels after insemination, an interaction with $\mathrm{P} 4$ supplementation might have interesting results. Macmillan (2010, page 46) stated that "although P4 supplementation has been demonstrated to have some advantages . . . novel variations in combination with variations to Ovsynch protocols deserve to be evaluated." Already in one study, the original Ovsynch protocol was combined with $\mathrm{P} 4$ supplementation after TAI (Arndt et al., 2009) in a small number of animals without showing an effect on the P/AI. It remains unknown whether $\mathrm{P} 4$ supplementation after TAI can interact with a modified Ovsynch protocol to increase $\mathrm{P} 4$ levels and fertility.

The first objective of this study was to evaluate the effect of delaying the second GnRH of the Ovsynch protocol up to $60 \mathrm{~h}$. We hypothesized that cows in the 60-h group would show increased P4 levels and P/AI compared with those in the traditional 48-h protocol. Furthermore, we expected to compensate for this difference with P4 supplementation after insemination because we expected to have an overall positive influence in $\mathrm{P} / \mathrm{AI}$. An additional objective was to examine the way that the body condition could influence the results of the above-mentioned treatments.

\section{MATERIALS AND METHODS}

\section{Animals and Experimental Design}

The study was conducted from November 2007 to April 2009 at a commercial dairy farm in Thüringen, Germany. The farm had a total of 1,548 dairy cows, of which 1,126 were lactating at the beginning of the study. Lactating cows were milked 3 times per day and were fed a TMR containing corn and grass silage and concentrates at levels that ensured ad libitum access. The herd was vaccinated and checked for bovine herpesvirus 1 twice a year, and positive animals were culled. The dairy herd software HERDE (DSP Agrosoft GmbH, Paretz, Germany) was used to record disorders and production and reproductive data. Almost all examinations and treatments were done by the same veterinarian.

After sample size estimation, where a difference of $10 \%$ in $\mathrm{P} / \mathrm{AI}$ was considered significant in a univariate analysis, 449 lactating Holstein-Friesian cows that did not meet the exclusion criteria were enrolled in the study. The farmer did not use synchronization protocols as a routine. Therefore, all animals were recruited for the study. A total of 398 cows (88.6\%) were eligible for analysis, whereas 51 cows $(11.4 \%)$ were excluded from the study; 24 of them $(5.3 \%)$ were detected in estrus the day of the $\mathrm{PGF}_{2 \alpha}$ application and the following and were inseminated. Ten cows $(2.2 \%)$ lost the P4releasing intravaginal device (PRID), 9 were removed from reproduction, 6 became severely ill, and 2 cows lacked documentation. An Ovsynch protocol was initiated between d 52 to 63 after calving (Figure 1). Each cow was given GnRH [100 $\mu \mathrm{g}$ of gonadorelin diacetate tetrahydrate (Ovarelin); CEVA Tiergesundheit GmbH, Düsseldorf, Germany], followed $7 \mathrm{~d}$ later by $\mathrm{PGF}_{2 \alpha}(25$ $\mathrm{mg}$ of Dinoprost and $33.6 \mathrm{mg}$ of Dinoprost-Trometamol (Enzaprost T); CEVA Tiergesundheit $\mathrm{GmbH}$ ). Thereafter, cows were blocked by parity and were randomly 


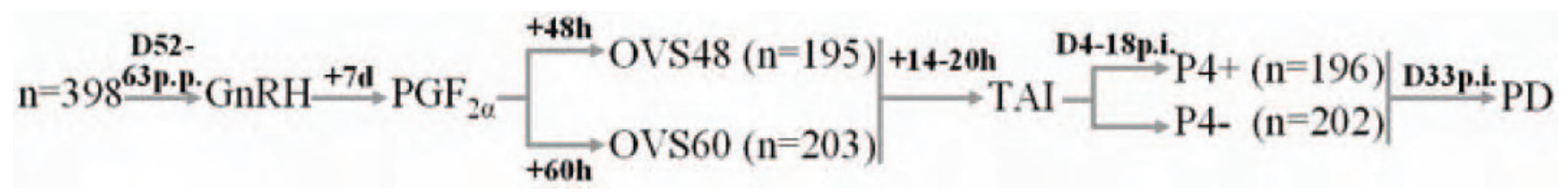

Figure 1. Experimental design of a combined use of Ovsynch protocols and progesterone supplementation postinsemination. TAI $=$ timed $\mathrm{AI} ; \mathrm{P} 4+, \mathrm{P} 4-=$ supplemented or not supplemented with progesterone, respectively; OVS48, OVS60 = ovulation synchronization with the $\mathrm{GnRH}$ injection at, respectively, 48 or $60 \mathrm{~h}$ after $\mathrm{PGF}_{2 \alpha} ; \mathrm{PD}=$ pregnancy diagnosis; p.p. = postpartum; p.i. = postinsemination.

allocated into 2 groups: the traditional Ovsynch protocol, with the second injection of GnRH following $48 \mathrm{~h}$ after $\mathrm{PGF}_{2 \alpha}$ (OVS48 group, $\left.\mathrm{n}=195\right)$, and a modified Ovsynch protocol, with the second injection of $\mathrm{GnRH}$ following $60 \mathrm{~h}$ after $\mathrm{PGF}_{2 \alpha}$ (OVS60 group, $\mathrm{n}=203$ ). All cows were bred by TAI 14 to $20 \mathrm{~h}$ after the second GnRH by 2 technicians, using frozen-thawed semen from multiple sires of proven fertility. On d 4 after TAI, a random $50 \%$ of the cows were supplemented with a PRID at $1.55 \mathrm{~g}$ (1.55 g of P4; CEVA Tiergesundheit $\mathrm{GmbH}$ ) for $14 \mathrm{~d}$ (d 18 postinsemination; P4+ group, $\mathrm{n}=196)$; the rest of the cows remained untreated (P4- group, $\mathrm{n}=202)$. Hence, 4 groups of animals were created: OVS48 P4- $(\mathrm{n}=97)$, OVS60 P4- $(\mathrm{n}=$ 105), OVS48 P4+ $(\mathrm{n}=98)$ and OVS60 P4+ $(\mathrm{n}=98)$. Each injection of $\mathrm{PGF}_{2 \alpha}$ and $\mathrm{GnRH}$ was given intramuscularly with a sterile needle for single use. Before insertion of a PRID, the vulva was washed with soap and water and dried. The PRID devices were moistened with $70 \%$ ethanol and inserted into the vagina with an applicator. The applicator was then removed, cleaned, and disinfected before using it again.

On d 4, 5, and 18 after TAI, a 4-mL blood sample from a random $50 \%$ of each group of the cows was taken from the vena caudalis mediana after disinfection of the area. The samples were stored on ice until centrifuged $\left(3,500 \times g\right.$ for 15 min at $\left.4^{\circ} \mathrm{C}\right)$ within $60 \mathrm{~min}$ after collection, and then plasma was stored at $-20^{\circ} \mathrm{C}$ until hormone analyses. In the endocrinology laboratory of the Clinic for Cattle, University of Veterinary Medicine, Hannover, Germany, plasma P4 was measured by a standard enzyme immunoassay according to the method of Prakash et al. (1987) and Beindorff et al. (Beindorff et al., 2009; Lüttgenau et al., 2011). Briefly, P4 was measured directly in $20 \mathrm{~mL}$ of plasma (antibody: P-1922 monoclonal anti-P4; Sigma, Steinheim, Germany; enzyme: 4-pregnen-3.20-dione3-O-carboxymethyloxime horseradish peroxidase; $\mathrm{H}$. H. D. Meyer, Physiology Weihenstephan, Technische Universitaet Muenchen, Freising, Germany). For each assay, the incubation was overnight. The standard curve was from 0.2 to $12.5 \mathrm{ng} / \mathrm{mL}$, and quality controls $(1.0$ and $3.0 \mathrm{ng} / \mathrm{mL}$ ) were within the linear range of measurement. Validation of the assay yielded a lower detection limit of $0.5 \mathrm{ng} / \mathrm{mL}$, whereas the upper limit was found at $4.0 \mathrm{ng} / \mathrm{mL}$. All samples with initially higher results were measured again after dilution. The intra- and interassay CV were $<10 \%$. After P4 analysis, a contamination of some blood samples of d 4 with P4, originating from the PRID, was assumed. Specifically, cows that had been treated with $\mathrm{P} 4$ on $\mathrm{d} 4$ showed higher P4 levels on the samples derived immediately after insertion of the intravaginal spiral compared with cows without P4 supplementation. In a small trial, it was confirmed that blood sampling performed directly after intravaginal application of the PRID without a change of gloves could lead to contamination of the samples with $\mathrm{P} 4$ and did not reflect the plasma P4 levels of the cows. Briefly, on d 4 postestrus, 2 cows were synchronized and blood samples were taken with clean gloves from the vena caudalis mediana after disinfection of the area. Immediately after sampling, blood collection was repeated twice for each cow using gloves that had previously touched a PRID device. In all 4 contaminated samples, P4 was found to be elevated 3 to 4 times compared with the first samples. Therefore, in our study, only samples from P4- cows were used for analysis of $\mathrm{P} 4$ on $\mathrm{d} 4$.

\section{Synchronization Rate, Pregnancy Diagnosis, and Pregnancy Loss}

Transrectal ultrasonography was performed with a 5-MHz, linear-array transducer (Sonovet 2000; Sonoace, Osteosys Co. Ltd., Seoul, Korea) on the days of the second GnRH and TAI, on the day after TAI, and on pregnancy diagnosis. Cows that had a follicle between 15 and $25 \mathrm{~mm}$ on the day of TAI or on the day of the second GnRH and with the absence of the follicle $1 \mathrm{~d}$ after were considered synchronized. For the analysis of $\mathrm{P} 4$, only the animals that were successfully synchronized were included. Pregnancy diagnosis was performed on d 33 after TAI. A cow was diagnosed as pregnant if embryonic heartbeats were detected. Pregnancy per AI was estimated by dividing the number of pregnant cows on $\mathrm{d} 33$ by the number of cows that were inseminated. In addition, pregnancy status of positive cows was reexamined by transrectal palpation between 
d 90 and 100 postinsemination to detect pregnancy loss. In cases of negative findings, ultrasound was used to confirm this finding. Pregnancy loss was calculated by the difference in pregnant animals between $\mathrm{d} 33$ and 90 .

\section{Documentation and Exclusion Criteria}

The health status of all cows was assessed during the first $3 \mathrm{~d}$ after parturition and during the late puerperium ( 28 to $42 \mathrm{~d}$ postpartum). Cows showing a severe or life-threatening illness (i.e., torsion of the uterus, severe dystocia with gross vaginal lacerations, severe mastitis) or cows that required surgical operation at any time were excluded from the study. Retained fetal membranes were defined as fetal membranes not expelled within $12 \mathrm{~h}$ and were treated with systemic and local antibiotics according to the treatment protocols of the farm. At late puerperium, each cow was examined with transrectal palpation to monitor uterine involution and with a vaginal speculum for purulent discharge. All cows with incomplete involution of the uterus (e.g., no repositioning in the pelvic canal, no symmetry of the horns, or both) or with any kind of mucopurulent material were excluded from the study. Uniform and translucent mucus in the absence of a fetid odor was defined as normal mucus.

At the time of the first GnRH injection, health status was assessed: cows with clinical mastitis, pyrexia, diarrhea, distinct lameness [score 3 to 5 in the lameness scoring system of Sprecher et al. (1997)], and other severe illnesses were excluded. The presence of ketones was determined in the urine (KetostixR; Bayer Co., Pittsburgh, PA) and was recorded on an ordinal scale. Cows with severe ketosis were also excluded from the study, and only cows with a small amount of ketone bodies and no other clinical signs were included in the model as a binary variable (presence or absence).

The BCS was graded from 1 to 5 , in 0.25 increments, as described by Edmonson et al. (1989). The BCS was assessed at calving (d 0), at puerperium (28 to $33 \mathrm{~d}$ postpartum), at the time of the first $\mathrm{GnRH}$ injection (52 to 63 d postpartum, BCS60), and on the day of ultrasonographic pregnancy diagnosis (90 to $100 \mathrm{~d}$ postpartum).

The 100-d milk production (MP100) of each cow was derived from the software of the farm and was included in the model as a continuous variable. The season was included in the model as a binary variable, with the months from April to September defined as summer months and those between October and March as winter months. Additionally, the cows were classified into 2 parity groups: primi- and multiparous cows.

\section{Statistical Analysis}

Where univariate analysis was used, differences in binary variables were evaluated with the use of chisquared analysis (PROC FREQ of SAS; SAS Institute Inc., Cary, NC). Because BCS measurements at different time points $(0,30,60,90 \mathrm{~d})$ were correlated, a stepwise logistic regression model (PROC LOGISTIC of SAS) was used to analyze and select the effect of BCS measured at different time points on pregnancy. Only the BCS60 showed a significant effect on pregnancy status and was considered in further analysis. A set of variables were used in the statistical model for their effect on pregnancy, namely, MP100, parity, season, synchronization protocol, P4 supplementation, and BCS60. Nonsignificant variables were removed from the model by using sums of squares types I and III (Wald-type) tests and $F$-statistics at $P<0.05$ rather than likelihood ratio tests. The $F$-ratios used in the ANOVA are identical to the Wald/rank (K) F-statistics as defined by Littell et al. (1999).

Finally, statistical analysis was carried out by application of a linear logistic model with a binary response variable, which is modeled as a binomial random variable $\left(y_{i}\right)$. The data were then analyzed with the GLIMMIX macro (Littell et al., 1999) using the following generalized linear model:

$$
\begin{gathered}
\operatorname{logit}\left(\pi_{r s t}\right)=\log \left(\frac{\pi_{r s t}}{1-\pi_{r s t}}\right)=\eta_{r s t}= \\
\phi+\alpha_{r}+\beta_{s}+b\left(y_{r s t}-\bar{y}_{t}\right)+\alpha_{r} b\left(y_{r s t}-\bar{y}_{t}\right),
\end{gathered}
$$

where $\pi_{r s t}$ is the probability of pregnancy; $\phi$ is the overall mean effect, $\alpha_{r}$ is the fixed effect of applying PRID (treated intravaginally for $14 \mathrm{~d}$ vs. untreated), $\beta_{s}$ is the fixed effect of retention of fetal membranes (retention vs. no retention), $b$ linear regressions of pregnancy on BCS of animal $t$ in PRID $v$ and in retention of fetal membranes $s, y_{v s t}$ are the BCS values, and $\bar{y}$ is the mean of BCS values, and $\alpha_{r} b\left(y_{v s t}-\bar{y}_{t}\right)$ is the fixed interaction effect between PRID and BCS60.

Least squares means were estimated on the logit scale and then back-transformed using the inverse link function, $\pi=\exp (x \beta) /[1+\exp (x \beta)]$, to the original scale (probability) applying the LSMEANS statement of SAS. Significant differences between least squares means were tested using a $t$-test procedure by inclusion of the PDIFF option in the LSMEANS statement of SAS. Standard errors of least squares means were calculated as described by Littell et al. (1999). For the analysis of P4 values, a generalized linear model with the use of PROC GLM of SAS was applied. The influ- 
ence of the synchronization protocol, the body condition, and the pregnancy status on $\mathrm{P} 4$ values on $\mathrm{d} 4,5$, and 18 after TAI was estimated in cows without P4 supplementation. For d 5 and 18, additional analyses were run, including all cows and the variables PRID, OVS, BCS60, pregnancy status, and all 2-way interactions in the models. All analyses were considered to be statistically significant at $P<0.05$ and as a tendency at $0.05 \leq P<0.10$.

\section{RESULTS}

The average DIM at TAI was $66 \pm 0.2 \mathrm{~d}$. The mean and median lactation number did not differ $(P=0.9)$ between the 4 groups, and for all the animals in the experiment they were $1.69 \pm 0.02$ and 2.0, respectively. The mean and median ML100 were $3,717 \pm 31 \mathrm{~kg}$ and $3,723 \mathrm{~kg}$, respectively. The mean and median BCS60 were $3 \pm 0.02$ and 3 . No significant difference was observed between the 4 groups in either variable (both $P$ $>0.10)$. Similarly, no difference was observed between the 4 groups in the proportion of animals with low BCS (Table 1). The proportion of cows that were synchronized was similar between groups and averaged $86.9 \%$ (Table 1).

\section{P/AI}

The overall P/AI was 41.2\% (164/398). Pregnancy per AI was not influenced by season, MP100, ketosis, lactation number, or BCS on d 0, 30, and 90 postpartum, and these variables were dropped from the model (Table 2). Pregnancy per AI was also similar between the 2 Ovsynch protocols (38.4\% vs. $44.1 \%$ for OVS60 vs. OVS48, respectively, $P=0.21)$. However, P4 supplementation tended to improve P/AI ( $44.4 \%$ vs. $38.1 \%$ for $\mathrm{P} 4+$ vs. $\mathrm{P} 4-$, respectively, $P=0.08)$. Cows suffering from the retention of fetal membranes had decreased $\mathrm{P} / \mathrm{AI}(21.4 \%$ vs. $42.7 \%, P=0.05)$. Similarly, BCS60 had an influence on $\mathrm{P} / \mathrm{AI}(P=0.002)$. Moreover, an interaction between BCS60 and P4 supplementation was apparent $(P=0.05)$; that is, $\mathrm{P} 4$ supplementation improved the $\mathrm{P} / \mathrm{AI}$ of only the better conditioned cows. As a result, $\mathrm{P} / \mathrm{AI}$ was significantly $(P<0.05)$ improved in supplemented cows compared with $\mathrm{P} 4-$ cows only when the BCS of the cows was $\geq 3.25$ (Figure 2). No other 2-way interactions with the variables Ovsynch, $\mathrm{P} 4$ supplementation, or Ovsynch $\times \mathrm{P} 4$ were significant.

The OVS48 cows supplemented with $\mathrm{P} 4$ showed $\mathrm{P} /$ AI of $50 \%$ and tended $(P=0.09)$ to differ from those in the other 3 groups, which slightly exceeded $38 \%$ (Table $1)$. To give insight into the 4 groups, further analyses excluding cows not being synchronized $(\mathrm{n}=52)$ were run (Table 1). In cows being synchronized and having a BCS60 $\geq 3(\mathrm{n}=220)$, an improvement of the P/AI with the supplementation with $\mathrm{P} 4$ was apparent $(\mathrm{P} 4+60 \%$ vs. $\mathrm{P} 4-47 \%, P=0.05)$. This increase was observed in both Ovsynch groups $(+11.4 \%$ in the OVS48 and $+13.7 \%$ in the OVS60 group), although statistically, it was evident only as a tendency because of the allocation of the cows into the 4 groups (Table 1). In cows being synchronized and having a BCS $<3$ ( $\mathrm{n}=$ 126), no improvement in $\mathrm{P} / \mathrm{AI}$ after $\mathrm{P} 4$ supplementation was noticed ( $\mathrm{P} 4-36.2 \%$ vs. $\mathrm{P} 4+35.3 \%, P=0.9)$, although a numerical increase in $\mathrm{P} / \mathrm{AI}$ was observed in the OVS48 group, and a similar decrease was observed in the OVS60 group.

\section{Pregnancy Loss}

Six cows (3.7\%) lost their conceptuses between d 33 and 90 of pregnancy. An effect of the Ovsynch protocol on embryo or fetus loss was observed because all the affected cows belonged to the OVS60 group $(P=0.01)$. On the contrary, they were equally distributed regarding P4 supplementation. Parity, lactation, season, and BCS did not affect pregnancy loss, and no interaction was observed between these variables. Moreover, P4 values on d 4, 5, and 18 did not influence pregnancy loss between d 33 and 90 .

Table 1. Synchronization and pregnancy per AI (P/AI), and categorization according to BCS at d 60 (BCS60) in the 4 groups derived from Ovsynch (OVS) and progesterone (P4) supplementation protocols ${ }^{1}$

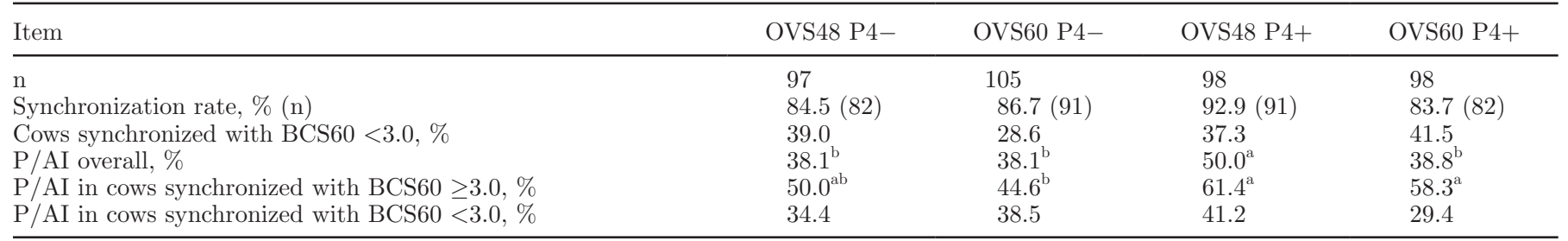

a,b Values within a row tend to differ $(0.05 \leq P<0.10)$.

${ }^{1}$ OVS48 = ovulation synchronization with the GnRH injection at $48 \mathrm{~h}$ after $\mathrm{PGF}_{2 \alpha}$; OVS60 = ovulation synchronization with the GnRH injection at $60 \mathrm{~h}$ after $\mathrm{PGF}_{2 \alpha} ; \mathrm{P} 4-=$ not supplemented with progesterone; $\mathrm{P} 4+=$ supplemented with progesterone; $\mathrm{BCS60}=\mathrm{BCS}$ assessed at the time of the first $\mathrm{GnRH}$ injection (52 to $63 \mathrm{~d}$ postpartum). 
PROGESTERONE SUPPLEMENTATION AFTER SYNCHRONIZATION

Interaction between P4 supplementation and BCS

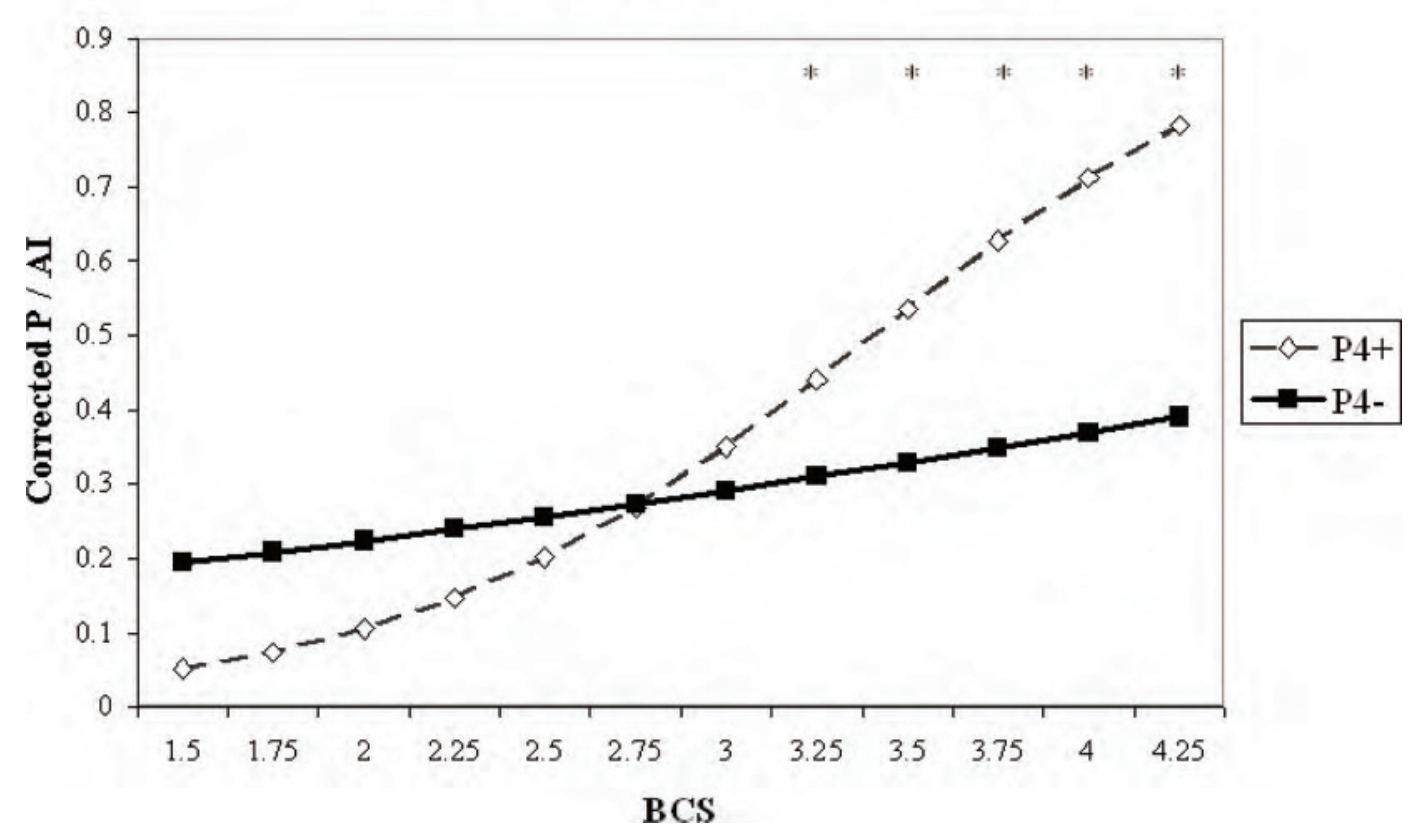

Figure 2. Effect of progesterone (P4) supplementation postinsemination on pregnancy per AI (P/AI) of Holstein-Friesian cows in different BCS categories using back-transformed least squares means. ${ }^{*} P<0.05$.

Table 2. Uncorrected pregnancy per AI (P/AI) and $P$-values of the variables under consideration ${ }^{1}$

\begin{tabular}{|c|c|c|c|c|}
\hline Variable and class & $\mathrm{n}$ & $\begin{array}{l}\text { Uncorrected } \\
\text { P/AI, \% }\end{array}$ & $F$-value & $P>F$ \\
\hline Season & & & 0.27 & 0.61 \\
\hline Summer & 198 & 41.5 & & \\
\hline Winter & 200 & 40.9 & & \\
\hline MP100 & 398 & & 0.08 & 0.78 \\
\hline Ketosis & & & 1.69 & 0.19 \\
\hline No & 362 & 42.3 & & \\
\hline Yes & 36 & 30.6 & & \\
\hline Parity & & & 0.18 & 0.67 \\
\hline 1 & 122 & 45.1 & & \\
\hline$>1$ & 276 & 39.5 & & \\
\hline BCS0 & 398 & & 0.75 & 0.39 \\
\hline BCS30 & 398 & & 0.99 & 0.32 \\
\hline BCS60 & 398 & & 9.92 & 0.001 \\
\hline BCS90 & 398 & & 0.19 & 0.67 \\
\hline RFM & & & 3.84 & 0.05 \\
\hline No & 370 & 42.7 & & \\
\hline Yes & 28 & 21.4 & & \\
\hline Ovsynch & & & 0.87 & 0.17 \\
\hline OVS48 & 195 & 44.1 & & \\
\hline OVS60 & 203 & 38.4 & & \\
\hline PRID & & & 3.17 & 0.08 \\
\hline No & 202 & 38.1 & & \\
\hline Yes & 196 & 44.4 & & \\
\hline
\end{tabular}

${ }^{1} \mathrm{MP100}=100-\mathrm{d}$ milk production; $\mathrm{BCS} 0=\mathrm{BCS}$ assessed at calving $(\mathrm{d}$ 0); BCS30 = BCS assessed at puerperium (28 to $33 \mathrm{~d}$ postpartum); BCS60 = BCS assessed at the time of the first GnRH injection (52 to $63 \mathrm{~d}$ postpartum); BCS90 = BCS assessed on the day of ultrasonographic pregnancy diagnosis (90 to $100 \mathrm{~d}$ postpartum); RFM = retained fetal membranes; OVS48 = ovulation synchronization with the GnRH injection at $48 \mathrm{~h}$ after $\mathrm{PGF}_{2 \alpha} ;$ OVS60 $=$ ovulation synchronization with the $\mathrm{GnRH}$ injection at $60 \mathrm{~h}$ after $\mathrm{PGF}_{2 \alpha} ; \mathrm{PRID}=$ progesterone-releasing intravaginal device (CEVA Tiergesundheit GmbH, Düsseldorf, Germany). 


\section{P4 Concentration After TAI}

The OVS60 group showed as a trend $(P=0.08)$ of having higher $\mathrm{P} 4$ values on $\mathrm{d} 4$ after TAI in comparison with the OVS48 group (Table 3). On d 5 and 18, cows that received $\mathrm{P} 4$ supplementation showed higher $\mathrm{P} 4$ blood levels than did the nonsupplemented cows $(P<$ 0.0001 and $P=0.01$, respectively; Table 3 ). Pregnant cows had higher $\mathrm{P} 4$ values on $\mathrm{d} 18$, in the analysis of the nonsupplemented cows (Table 3), all cows, and the cows with $\mathrm{P} 4$ supplementation (data not shown). No effect $(P>0.05)$ of body condition on $\mathrm{P} 4$ levels was apparent in any analysis, nor was any interaction between variables statistically significant. A strong trend was observed for cows having a $\mathrm{P} 4$ value (d 5 after TAI) $\geq 2 \mathrm{ng} / \mathrm{mL}$ to show better $\mathrm{P} / \mathrm{AI}$ than cows having $\mathrm{P} 4$ values $<2 \mathrm{ng} / \mathrm{mL}$ (45.5 vs. $30.9 \%$, respectively, $P=$ 0.058).

\section{DISCUSSION}

In our study, the modification of the OVS48 protocol by prolonging the time of the second $\mathrm{GnRH}$ to $60 \mathrm{~h}$ showed no effect on P/AI. The further increase in time of an additional $12 \mathrm{~h}$ probably allowed follicles to grow larger, producing larger corpora lutea, increased blood flow, or both to these structures, which were competent to elevate (albeit weakly) P4 levels. Previous studies have shown that a higher follicular and luteal blood flow in Ovsynch-treated cows can be achieved when the second $\mathrm{GnRH}$ injection is performed $60 \mathrm{~h}$ instead of $40 \mathrm{~h}$ after the $\mathrm{PGF}_{2 \alpha}$ (Bollwein et al., 2010). The prolongation of the time interval between $\mathrm{PGF}_{2 \alpha}$ and the second GnRH injection had no significant effect on $\mathrm{P} 4$ concentrations in the study by Bollwein et al. (2010), probably because of the small number of cows and the different days of measurement (d 7 vs. $\mathrm{d} 5$ in our study). A relationship between the follicular blood flow on the one hand and the quality of the oocyte, the embryo, and the conception rate in heifers, on the other hand, has been established (Siddiqui et al., 2009a, b). Pregnancy per AI intervals similar to those in our study are described for a 56-h interval to the second $\mathrm{GnRH}$ in a timed-insemination Ovsynch protocol (Brusveen et al., 2008). Unfortunately, in that study, the 56-h protocol was not directly compared with an OVS48 protocol. According to Robinson et al. (2005), cows inseminated after using an Ovsynch protocol are more likely to be affected by embryonic mortality. A possible reason for this observation is a low plasma $\mathrm{P} 4$ level, which may be caused by the development of a small corpus luteum after the ovulation of immature small follicles (Robinson et al., 2005). Although that was not the case in the OVS60 group, no apparent improvement in $\mathrm{P} / \mathrm{AI}$ was noticed. On the contrary, all pregnancy losses were noticed in the OVS60 protocol, although the proportion was still small. Poor embryo quality attributable to aged oocytes cannot be excluded when protocols that delay ovulation are implemented (Cerri et al., 2009). On the basis of our study and those of others (Peters and Pursley, 2003; Brusveen et al., 2008; Cerri et al., 2009), a time interval between $\mathrm{PGF}_{2 \alpha}$ and the second GnRH of 48 to $60 \mathrm{~h}$ seems to be the right balance to achieve good $\mathrm{P} / \mathrm{AI}$ rates in dairy farms. Moreover, in our study, cows with a low BCS had lower P/AI independently of the protocol (Table 1). Yamada (2005) reported that after Ovsynch/TAI in cows, improved P/ AI can be achieved when the BCS is at least 3.75 at the dry period and 3.0 on the day of Ovsynch, which fully agrees with the results in our study.

Recently, Arndt et al. (2009) conducted a study similar to ours that combined the classical Ovsynch protocol with P4 supplementation after insemination. They noticed no effect on the P/AI caused by $\mathrm{P} 4$ supplemen-

Table 3. Progesterone values (mean \pm SEM) in the blood of synchronized Holstein-Friesian cows on d 4 (P4D4), 5 (P4D5), and 18 (P4D18) postinsemination in different groups ${ }^{1}$

\begin{tabular}{llccc}
\hline Variable & Level & P4D4 & P4D5 & P4D18 \\
\hline OVS $^{2}$ & OVS48 $(\mathrm{n}=44)$ & $1.6 \pm 0.2^{\mathrm{C}}$ & $2.4 \pm 0.2^{\mathrm{B}}$ & $5.9 \pm 0.5^{\mathrm{A}}$ \\
& OVS60 $(\mathrm{n}=48)$ & $2.1 \pm 0.2^{\mathrm{C}}$ & $2.7 \pm 0.2^{\mathrm{B}}$ & $6.7 \pm 0.6^{\mathrm{A}}$ \\
$\mathrm{P} 4$ & $\mathrm{P} 4-(\mathrm{n}=92)$ & $\mathrm{NA}$ & $2.6 \pm 0.2^{\mathrm{b}, \mathrm{B}}$ & $6.3 \pm 0.4^{\mathrm{b}, \mathrm{A}}$ \\
& $\mathrm{P} 4+(\mathrm{n}=90)$ & $2.0 \pm 0.2^{\mathrm{C}}$ & $4.9 \pm 0.2^{\mathrm{a}, \mathrm{B}}$ & $7.8 \pm 0.4^{\mathrm{a}, \mathrm{A}}$ \\
$\mathrm{PD}$ & $\mathrm{PD}-(\mathrm{n}=51)$ & $2.6 \pm 0.2^{\mathrm{B}}$ & $4.8 \pm 0.5^{\mathrm{b}, \mathrm{A}}$ \\
& $\mathrm{PD}+(\mathrm{n}=41)$ & $1.7 \pm 0.2^{\mathrm{C}}$ & $2.5 \pm 0.2^{\mathrm{B}}$ & $8.1 \pm 0.5^{\mathrm{a}, \mathrm{A}}$ \\
\hline
\end{tabular}

${ }^{\mathrm{a}, \mathrm{b}}$ Values within a column and variable with different superscripts differ $(P<0.05)$.

${ }^{\mathrm{A}-\mathrm{C}}$ Values within a row with different superscripts differ $(P<0.05)$.

${ }^{1}$ OVS48 = ovulation synchronization with the GnRH injection at $48 \mathrm{~h}$ after $\mathrm{PGF}_{2 \alpha}$; OVS60 = ovulation synchronization with the $\mathrm{GnRH}$ injection at $60 \mathrm{~h}$ after $\mathrm{PGF}_{2 \alpha} ; \mathrm{P} 4-=$ not supplemented with progesterone; $\mathrm{P} 4+$ $=$ progesterone supplementation from $\mathrm{d} 4$ to 18 postinsemination; $\mathrm{PD}-=$ negative pregnancy diagnosis; PD + $=$ positive pregnancy diagnosis; $\mathrm{NA}=$ not analyzed.

${ }^{2}$ Animals without $\mathrm{P} 4$ supplementation. 
tation (Arndt et al., 2009). Moreover, P4 supplementation had no significant effect on the plasma P4 levels, in contrast to the results of other studies, including ours. An increase in hepatic $\mathrm{P} 4$ clearance resulting from increased blood flow to the liver, based on the findings of Sangsritavong et al. (2002), has been hypothesized (Arndt et al., 2009). Reasons for the missing effect on P4 levels and fertility might be the use of a different intravaginal $\mathrm{P} 4$ device containing different amounts of P4 and the relatively small number of animals used (Van Cleeff et al., 1996; Arndt et al., 2009). In our study, supplementation of $\mathrm{P} 4$ from d 4 to 18 had a positive effect in the combination with the Ovsynch protocols in all but 1 subgroup. The low $\mathrm{P} / \mathrm{AI}$ of cows in the P4+OVS60 treatment was surprising at first view, but could be explained partly by the greater number of cows with low BCS that failed to be synchronized through the Ovsynch protocol that belonged to that group (Table 1). Moreover, the relatively small number of cows in the 4 subgroups (with animals of low BCS60 and synchronized) does not allow us to draw sound statistical conclusions. Nonetheless, after the exclusion of these animals, we found that P4 supplementation resulted in an increase in the $\mathrm{P} / \mathrm{AI}$ of $11.4 \%$ in the OVS48 group and of $13.7 \%$ in the OVS60 group. This increase is very close to the results obtained by Larson et al. (2007), who found a treatment effect of $13 \%$ and an overall $\mathrm{P} / \mathrm{AI}$ of $48 \%$ after the supplementation of P4. Several studies have also shown an increase of fertility in different subgroups (Villarroel et al., 2004; Ghasemzadeh-Nava et al., 2007; Larson et al., 2007). Differences in the study design have to be considered because using only repeat breeder cows (Villarroel et al., 2004; Ghasemzadeh-Nava et al., 2007) or insemination after detected estrous in young cows (Larson et al., 2007) can result in factors influencing the fertility. Nevertheless, these studies report similar increases of almost $10 \%$ in $\mathrm{P} / \mathrm{AI}$. Other studies have found a negative effect on $\mathrm{P} / \mathrm{AI}$ if $\mathrm{P} 4$ is supplemented directly after breeding (Van Cleeff et al., 1991).

Several studies prove the effect of energy balance on general parameters of fertility (Pryce et al., 2001; Gossen et al., 2006) and directly on plasma P4 concentrations during the early postpartum period (Villa-Godoy et al., 1988; Spicer et al., 1990; Villa-Godoy et al., 1990; Spicer et al., 1993). A negative energy balance decreased the body condition, impaired the luteal development, and reduced the $\mathrm{P} 4$ secretion in vivo and in vitro in nulliparous Holstein heifers after feed restriction (Villa-Godoy et al., 1990). The authors concluded that negative energy balance can result in a lower $\mathrm{P} 4$ level because of less luteal tissue and in reduced steroidogenic activity per luteal cell because of reduced basal and LH-induced P4 secretion (Villa-Godoy et al., 1990). Moreover, a study in beef cattle showed that that the efficiency of a P4-based synchronization protocol was influenced by the energy intake of the cows (Wichtel et al., 2008). Although, in our study, the positive effect of P4 supplementation was observed mainly on the better conditioned cows, we could not find a relationship between the BCS and the plasma P4 concentrations on the fourth and fifth day after insemination. Possibly a correlation between $\mathrm{P} 4$ and BCS cannot be proved for single days of P4 measurements, but for a whole cycle with daily measurements. Beltman et al. (2009), for instance, found a significant relationship between BCS and $\mathrm{P} 4$ levels on $\mathrm{d} 3$, but not on the following days. Moreover, it is known that low BCS suppresses oocyte quality (Snijders et al., 2000). Thus, the effect of P4 supplementation after TAI is expected to be compromised. Forde et al. (2009) showed that P4 positively affects expression of genes that are associated with triglyceride synthesis and glucose transport as parts of the histiotrophic components for the embryo. Clemente et al. (2009) conclude that P4 has an indirect effect on embryo development mainly because of P4-induced changes in the endometrium. If preparation of the endometrium for conceptus elongation is susceptible to metabolic changes and the nutrition regimen (Leroy et al., 2008), then only better conditioned cows can profit from elevated P4 levels after TAI. Maternal nutrition and energy balance influence the nutrients and local growth factors provided to the developing zygote in the oviduct (Mcguire et al., 1992; Pushpakumara et al., 2002). Nonetheless, further study on the exact influence of metabolic status on oocyte quality, preparation of the endometrium, and development of the early embryo will provide valuable information for possible interactions with $\mathrm{P} 4$ supplementation.

\section{CONCLUSIONS}

In conclusion, a low body condition at TAI had a negative influence on $\mathrm{P} / \mathrm{AI}$ independent of treatment. Progesterone supplementation from d 4 to 18 postinsemination can be a useful tool to improve the P/AI of cows synchronized independently of the protocol. In our study, the average P/AI of $38 \%$ was increased by almost $25 \%$ in cows that were proven synchronized, were better conditioned, and were supplemented with P4 after insemination. Although an overall improvement of the $\mathrm{P} / \mathrm{AI}$ by $8 \%$ was achieved with $\mathrm{P} 4$ supplementation after insemination, the authors are not recommending its use for animals with a low BCS $(<3.0)$ because these animals are not in an optimal physical state for fertilization or maintaining pregnancy. 


\section{ACKNOWLEDGMENTS}

The authors wish to thank CEVA Santé Animale (Libourne, France) for providing the medicaments and for the financial support of this study.

\section{REFERENCES}

Arndt, W. J., A. J. Holle, M. L. Bauer, J. D. Kirsch, D. E. Schimek, K. G. Odde, and K. A. Vonnahme. 2009. Effect of post-insemination progesterone supplementation on pregnancy rate in dairy cows. Can. J. Vet. Res. 73:271-274

Beindorff, N., A. Honnens, Y. Penno, V. Paul, and H. Bollwein. 2009 Effects of human chorionic gonadotropin on luteal blood flow and progesterone secretion in cows and in vitro-microdialyzed corpora lutea. Theriogenology 72:528-534.

Beltman, M. E., P. Lonergan, M. G. Diskin, J. F. Roche, and M. A. Crowe. 2009. Effect of progesterone supplementation in the first week post conception on embryo survival in beef heifers. Theriogenology 71:1173-1179.

Bollwein, H., D. Prost, S. E. Ulbrich, H. Niemann, and A. Honnens. 2010. Effects of a shortened preovulatory follicular phase on genital blood flow and endometrial hormone receptor concentrations in Holstein-Friesian cows. Theriogenology 73:242-249.

Brusveen, D. J., A. P. Cunha, C. D. Silva, P. M. Cunha, R. A. Sterry, E. P. Silva, J. N. Guenther, and M. C. Wiltbank. 2008. Altering the time of the second gonadotropin-releasing hormone injection and artificial insemination (AI) during Ovsynch affects pregnancies per AI in lactating dairy cows. J. Dairy Sci. 91:1044-1052.

Butler, W. R. 2000. Nutritional interactions with reproductive performance in dairy cattle. Anim. Reprod. Sci. 60-61:449-457.

Cerri, R. L. A., H. M. Rutigliano, R. C. Chebel, and J. E. P. Santos. 2009. Period of dominance of the ovulatory follicle influences embryo quality in lactating dairy cows. Reproduction 137:813-823.

Clemente, M., J. de La Fuente, T. Fair, A. Al Naib, A. Gutierrez-Adan J. F. Roche, D. Rizos, and P. Lonergan. 2009. Progesterone and conceptus elongation in cattle: A direct effect on the embryo or an indirect effect via the endometrium? Reproduction 138:507-517.

Edmonson, A. J., I. J. Lean, L. D. Weaver, T. Farver, and G. Webster. 1989. A body condition scoring chart for Holstein dairy cows. J. Dairy Sci. 72:68-78.

Forde, N., F. Carter, T. Fair, M. A. Crowe, A. C. Evans, T. E. Spencer, F. W. Bazer, R. McBride, M. P. Boland, P. O'Gaora, P. Lonergan, and J. F. Roche. 2009. Progesterone-regulated changes in endometrial gene expression contribute to advanced conceptus development in cattle. Biol. Reprod. 81:784-794.

Ghasemzadeh-Nava, H., H. Kohsari, and P. Tajik. 2007. Maintenance of pregnancy in repeat breeder dairy cows by CIDR administration after breeding. Pak. J. Biol. Sci. 10:2402-2406.

Gossen, N., S. Fietze, S. Mosenfechtel, and M. Hoedemaker. 2006 Relationship between body condition (back fat thickness and body condition scoring) and fertility in dairy cows (German Black Pied/ HF). Dtsch. Tierarztl. Wochenschr. 113:171-172, 174-177.

Green, M. P., M. G. Hunter, and G. E. Mann. 2005. Relationships between maternal hormone secretion and embryo development on day 5 of pregnancy in dairy cows. Anim. Reprod. Sci. 88:179-189.

Inskeep, E. K. 2004. Preovulatory, postovulatory, and postmaternal recognition effects of concentrations of progesterone on embryonic survival in the cow. J. Anim. Sci. 82(E-Suppl.):24-39.

Larson, S. F., W. R. Butler, and W. B. Currie. 2007. Pregnancy rates in lactating dairy cattle following supplementation of progesterone after artificial insemination. Anim. Reprod. Sci. 102:172-179.

Leroy, J. L. M. R., A. Van Soom, G. Opsomer, I. G. F. Goovaerts, and P. E. J. Bols. 2008. Reduced fertility in high-yielding dairy cows: Are the oocyte and embryo in danger? Part II-Mechanisms linking nutrition and reduced oocyte and embryo quality in highyielding dairy cows. Reprod. Domest. Anim. 43:623-632.

Littell, R., G. Milliken, W. Stroup, and R. Wolfinger. 1999. SAS System for Mixed Models. 1st ed. SAS Inst. Inc., Cary, NC.
Lüttgenau, J., N. Beindorff, S. E. Ulbrich, J. P. Kastelic, and H. Bollwein. 2011. Low plasma progesterone concentrations are accompanied by reduced luteal blood flow and increased size of the dominant follicle in dairy cows. Theriogenology 76:12-22.

Macmillan, K. L. 2010. Recent advances in the synchronization of estrus and ovulation in dairy cows. J. Reprod. Dev. 56:S42-S47.

Mann, G. E., M. D. Fray, and G. E. Lamming. 2006. Effects of time of progesterone supplementation on embryo development and interferon-tau production in the cow. Vet. J. 171:500-503.

Mann, G. E., and G. E. Lamming. 1999. The Influence of progesterone during early pregnancy in cattle. Reprod. Domest. Anim. $34: 269-274$

Mann, G. E., and G. E. Lamming. 2001. Relationship between maternal endocrine environment, early embryo development and inhibition of the luteolytic mechanism in cows. Reproduction 121:175-180.

Mann, G. E., P. Merson, M. D. Fray, and G. E. Lamming. 2001. Conception rate following progesterone supplementation after second insemination in dairy cows. Vet. J. 162:161-162.

Mawhinney, I., H. Biggadike, and B. Drew. 1999. Field trial of a planned breeding regimen for dairy cows, using gonadotrophinreleasing hormone and prostaglandin $\mathrm{F}_{2 \alpha}$. Vet. Rec. 145:551-554.

McGuire, M. A., J. L. Vicini, D. E. Bauman, and J. J. Veenhuizen. 1992. Insulin-like growth-factors and binding-proteins in ruminants and their nutritional regulation. J. Anim. Sci. 70:2901-2910.

Moreira, F., C. Risco, M. F. A. Pires, J. D. Ambrose, M. Drost, M. DeLorenzo, and W. W. Thatcher. 2000. Effect of body condition on reproductive efficiency of lactating dairy cows receiving a timed insemination. Theriogenology 53:1305-1319.

Mussard, M. L., C. R. Burke, E. J. Behlke, C. L. Gasser, and M L. Day. 2007. Influence of premature induction of a luteinizing hormone surge with gonadotropin-releasing hormone on ovulation, luteal function, and fertility in cattle. J. Anim. Sci. 85:937-943.

Peters, M. W., and J. R. Pursley. 2003. Timing of final GnRH of the Ovsynch protocol affects ovulatory follicle size, subsequent luteal function, and fertility in dairy cows. Theriogenology 60:11971204

Prakash, B. S., H. H. Meyer, E. Schallenberger, and D. F. van de Wiel. 1987. Development of a sensitive enzymeimmunoassay (EIA) for progesterone determination in unextracted bovine plasma using the second antibody technique. J. Steroid Biochem. 28:623-627.

Pryce, J. E., M. P. Coffey, and G. Simm. 2001. The relationship between body condition score and reproductive performance. J. Dairy Sci. 84:1508-1515.

Pursley, J. R., M. O. Mee, and M. C. Wiltbank. 1995. Synchronization of ovulation in dairy cows using $\mathrm{PGF}_{2 \alpha}$ and $\mathrm{GnRH}$. Theriogenology 44:915-923.

Pushpakumara, P. G. A., R. S. Robinson, K. J. Demmers, G. E. Mann, K. D. Sinclair, R. Webb, and D. C. Wathes. 2002. Expression of the insulin-like growth factor (IGF) system in the bovine oviduct at oestrus and during early pregnancy. Reproduction 123:859-868.

Robinson, N. A., K. E. Leslie, and J. S. Walton. 1989. Effect of treatment with progesterone on pregnancy rate and plasma concentrations of progesterone in Holstein cows. J. Dairy Sci. 72:202-207.

Robinson, R. S., A. J. Hammond, M. G. Hunter, and G. E. Mann. 2005. The induction of a delayed post-ovulatory progesterone rise in dairy cows: A novel model. Domest. Anim. Endocrinol. $28: 285-295$.

Sangsritavong, S., D. K. Combs, R. Sartori, L. E. Armentano, and M. C. Wiltbank. 2002. High feed intake increases liver blood flow and metabolism of progesterone and estradiol- $17 \beta$ in dairy cattle. J. Dairy Sci. 85:2831-2842.

Schmitt, E. J., T. Diaz, M. Drost, and W. W. Thatcher. 1996. Use of a gonadotropin-releasing hormone agonist or human chorionic gonadotropin for timed insemination in cattle. J. Anim. Sci. 74:1084-1091.

Siddiqui, M. A., M. Almamun, and O. J. Ginther. 2009a. Blood flow in the wall of the preovulatory follicle and its relationship to pregnancy establishment in heifers. Anim. Reprod. Sci. 113:287-292.

Siddiqui, M. A. R., E. L. Gastal, M. O. Gastal, M. Almamun, M. A. Beg, and O. J. Ginther. 2009b. Relationship of vascular perfusion 
of the wall of the preovulatory follicle to in vitro fertilisation and embryo development in heifers. Reproduction 137:689-697.

Snijders, S. E. M., P. Dillon, D. O'Callaghan, and M. P. Boland. 2000. Effect of genetic merit, milk yield, body condition and lactation number on in vitro oocyte development in dairy cows. Theriogenology 53:981-989.

Souza, A. H., H. Ayres, R. M. Ferreira, and M. C. Wiltbank. 2008. A new presynchronization system (Double-Ovsynch) increases fertility at first postpartum timed AI in lactating dairy cows. Theriogenology 70:208-215.

Spicer, L. J., W. B. Tucker, and G. D. Adams. 1990. Insulin-like growth factor-I in dairy cows: Relationships among energy balance, body condition, ovarian activity, and estrous behavior. J. Dairy Sci. 73:929-937.

Spicer, L. J., R. K. Vernon, W. E. Tucker, R. P. Wettemann, J. F. Hogue, and G. D. Adams. 1993. Effects of inert fat on energy balance, plasma concentrations of hormones, and reproduction in dairy cows. J. Dairy Sci. 76:2664-2673.

Sprecher, D. J., D. E. Hostetler, and J. B. Kaneene. 1997. A lameness scoring system that uses posture and gait to predict dairy cattle reproductive performance. Theriogenology 47:1179-1187.

Stronge, A. J., J. M. Sreenan, M. G. Diskin, J. F. Mee, D. A. Kenny, and D. G. Morris. 2005. Post-insemination milk progesterone concentration and embryo survival in dairy cows. Theriogenology 64:1212-1224.

Taponen, J., T. Katila, and H. Rodriguez-Martinez. 1999. Induction of ovulation with gonadotropin-releasing hormone during proestrus in cattle: Influence on subsequent follicular growth and luteal function. Anim. Reprod. Sci. 55:91-105.

Van Cleeff, J., M. Drost, and W. W. Thatcher. 1991. Effects of postinsemination progesterone supplementation on fertility and subsequent estrous responses of dairy heifers. Theriogenology 36:795807.
Van Cleeff, J., K. L. Macmillan, M. Drost, M. C. Lucy, and W. W. Thatcher. 1996. Effects of administering progesterone at selected intervals after insemination of synchronized heifers on pregnancy rates and resynchronization of returns to service. Theriogenology 46:1117-1130.

Villa-Godoy, A., T. L. Hughes, R. S. Emery, L. T. Chapin, and R. L. Fogwell. 1988. Association between energy balance and luteal function in lactating dairy cows. J. Dairy Sci. 71:1063-1072.

Villa-Godoy, A., T. L. Hughes, R. S. Emery, W. J. Enright, A. D. Ealy, S. A. Zinn, and R. L. Fogwell. 1990. Energy balance and body condition influence luteal function in Holstein heifers. Domest. Anim. Endocrinol. 7:135-148.

Villarroel, A., A. Martino, R. H. BonDurant, F. Deletang, and W. M. Sischo. 2004. Effect of post-insemination supplementation with PRID on pregnancy in repeat-breeder Holstein cows. Theriogenology 61:1513-1520.

Wathes, D. C., M. Fenwick, Z. Cheng, N. Bourne, S. Llewellyn, D. G. Morris, D. Kenny, J. Murphy, and R. Fitzpatrick. 2007. Influence of negative energy balance on cyclicity and fertility in the high producing dairy cow. Theriogenology 68(Suppl. 1):S232-S241.

Wichtel, J. J., E. Charmley, G. F. Richardson, J. L. Duynisveld, and R. Lofstedt. 2008. Effects of postpartum energy intake on pregnancy rates in beef cattle subjected to GnRH- or CIDR-based timed artificial insemination protocols. Can. J. Anim. Sci. 88:439-447.

Wiltbank, J. N., H. W. Hawk, H. E. Kidder, W. G. Black, L. C. Ulberg, and L. E. Casida. 1956. Effect of progesterone therapy on embryo survival in cows of lowered fertility. J. Dairy Sci. 39:456-461.

Yamada, K. 2005. Development of ovulation synchronization and fixed time artificial insemination in dairy cows. J. Reprod. Dev. $51: 177-186$. 